\title{
Gametófitos y esporófitos jóvenes de cuatro especies de helechos del género Pteris (Pteridaceae) naturalizadas en América
}

\author{
Olga G. Martínez \\ Herbario MCNS, Facultad de Ciencias Naturales, Universidad Nacional de Salta, Av. Bolivia 5150, 4400 Salta, \\ Argentina; martinezog@gmail.com
}

Recibido 27-V-2009. Corregido 13-IX-2009. Aceptado 13-X-2009.

\begin{abstract}
Gametophytes and young sporophytes of four species of the fern genus Pteris (Pteridaceae) naturalized in the American continent. The pantropical fern genus Pteris L. has about 250 species of which 60 occur in the American continent. We studied the morphogenesis of the gametophyte, and the morphology of the young sporophytes of four species: P. cretica, P. ensiformis, P. multifida and P.vittata, together with a palynological analysis that includes the ability of spores to germinate. Gametophytes were obtained trough in vitro culture techniques with agar-gellified Knudson medium. Young sporophytes were placed in earth-sand $(3: 1)$ sterile substrate. We used light and SEM microscopy. Triletes spores predominate, but monolete, tetralete, and other types of apertura are often found. The viability of spores is not affected by the variation, so the term spore polymorphism is applied to the condition occurring among these species. Spore polymorphism is similar in $P$. cretica and P. multifida. Germination occurs following the Vittaria type, 3-7 days after the sowing. Filamentous, 3-5 celled gametophytes were found in P. cretica, P. multifida and P. vittata, and 7-9 celled in P. ensiformis. Development of gametophytes takes place following Adiantum type and Ceratopteris type. The symmetry of the laminae differ in gametophytes, those of $P$. ensiformis and $P$. multifida are similar and differ from the other two species, $P$. cretica and $P$. vittata. Gametophytes of $P$. ensiformis, $P$. multifida and $P$. vittata are bisexual and protandric, while male gametophytes were found in $P$. cretica. Antheridia correspond to the common leptosporangiate type; they are cylindric in $P$. vittata and ovoid in the other three species. Archegonia necks have 4 rows of 4 cells each. The sporophytes complete their development 3 months after sowing, and have indument close to the adult plants. P. cretica shows obligated apogamy. Rev. Biol. Trop. 58 (1): 89-102. Epub 2010 March 01.
\end{abstract}

Key words: Pteris, spores, gametophyte development, young sporophytes, apogamy.

El género Pteris L. es pantropical; reúne aproximadamente 250 especies, 60 de las cuales crecen en América. Smith et al. (2006) consideran que el origen de este género probablemente no sea monofilético.

Este trabajo tiene como objetivo brindar información sobre la morfogénesis de los gametófitos de cuatro especies de Pteris L. naturalizadas en el continente americano, $P$. cretica L, P. ensiformis Burm.f., P. multifida Poir. y $P$. vittata L. Se realizó además un análisis palinológico relacionado con la viabilidad de las esporas y una descripción de la estructura de los esporófitos jóvenes.
Algunos aspectos de la fase sexual de estos helechos han sido abordados por distintos autores. Laird \& Sheffield (1986) analizaron la estructura de los gametangios y su relación con la apogamia en P. cretica; Kawakami et al. (1995) indujeron la formación de esporófitos apogámicos y estudiaron su morfología en $P$. multifida. La especie más estudiada es $P$. vittata. Ito (1962) determinó la capacidad de regeneración de los gametófitos de esta especie; Kato (1963, 1969) obtuvo callos sometiendo a los gametófitos a períodos de oscuridad y estudió, experimentalmente, el efecto de varios factores sobre ellos; Beri \& Bir (1993) determinaron los 
cambios bioquímicos producidos por el almacenamiento de las esporas; Prada et al. (2008) aportaron datos sobre la expresión sexual de $P$. vittata en relación con el medio de cultivo y Zhang et al. (2008) describieron el desarrollo de los gametófitos de $P$. ensiformis y $P$. vittata, entre otras especies prevenientes de China.

Los aportes a la palinología de especies aquí estudiadas fueron realizados por Nayar et al. (1964), Erdtman \& Sorsa (1971), Huang (1981), Tryon \& Tryon (1982), Michelena (1989), Tryon \& Lugardon (1991) y ArreguínSánchez (1997). La variabilidad morfológica de las esporas en Pteris fue presentada por Sladkov (1957), Nayar \& Devi (1966), Devi (1977) y Martínez \& Morbellli (2009), aunque ninguno de ellos hace referencia a la viabilidad de estas esporas atípicas.

Algunos aspectos morfológicos de los esporófitos jóvenes de Pteris fueron descritos por Mendoza et al. (1997) para P. berteroana Agardh. Huang et al. (2006) compararon esporófitos jóvenes de ejemplares diploides y triploides de $P$. fauriei Hieron y Letelier \& Peñailillo (2007) se refirieron a $P$. chilensis Desv.

Pteris presenta dificultades en la determinación de sus especímenes, por lo que el aporte de estudios de las primeras etapas de desarrollo del esporófito podría contribuir a un mejor conocimiento del grupo con datos que caractericen a sus taxones y permitan determinarlos desde etapas tempranas en su ambiente natural.

\section{MATERIALES Y MÉTODOS}

La obtención de gametófitos se realizó mediante cultivos in vitro. Los ejemplares de referencia se depositaron en el Herbario "Museo de Ciencias Naturales de Salta", Salta, Argentina (MCNS). Material estudiado: P. cretica: ARGENTINA: Salta, Quebrada Los Berros, Martínez 820. P. ensiformis: EEUU: California, Los Angeles, MCNS 1814. P. multifida: EEUU: California, Los Angeles, MCNS 1810. P. vittata: ARGENTINA: Jujuy, Libertador General San Martín, Martínez 1399.
Las esporas fueron separadas de restos vegetales con una malla con poros de $80 \mu \mathrm{m}$, desinfectadas con hipoclorito de sodio $10 \%$ acuoso durante 10 minutos y sembradas durante las 2 primeras semanas desde su colección. Se utilizó solución nutritiva de Knudson (modificada por Steeves et al. 1955) gelificada con agar $10 \mathrm{~g} / \mathrm{l}$, con $\mathrm{pH}$ ajustado a 6 con $\mathrm{ClH}, \mathrm{KOH}$ o $\mathrm{NaOH}$ al $1 \%$, y esterilizada en autoclave durante 20 minutos a 1 atmósfera de presión.

La siembra se realizó en cápsulas de Petri de $5 \mathrm{~cm}$ de diámetro y los repiques de gametófitos en frascos de $5 \mathrm{~cm}$ de diámetro por $7 \mathrm{~cm}$ de alto. Los cultivos se mantuvieron estériles durante un año en cámara de cultivo a $25 \pm 2^{\circ} \mathrm{C}$ con fotoperíodo de 16 horas de intensidad luminosa de $10 \mathrm{~W} \cdot \mathrm{m}^{-2}$. Los esporófitos fueron trasladados a un sustrato estéril formado por 3 partes de tierra y 1 de arena donde se mantuvieron seis meses.

Para el análisis palinológico se consideraron el diámetro polar (DP) y el diámetro ecuatorial (DE) incluidas las ornamentaciones de la pared, salvo en $P$. ensiformis. Las medidas son el resultado del promedio de 20 mediciones por cada ejemplar. Para la descripción de la ornamentación se utilizaron las propuestas de Lellinger \& Taylor (1997) y Punt et al. (2007). El contenido celular en las esporas se determinó con carmín acético. El estudio palinológico con microscopía de luz se realizó sobre esporas montadas en gelatina-glicerina y, para su estudio, con microscopía electrónica de barrido con esporas montadas sobre tacos de metal con cinta adhesiva doble faz.

Para la obtención de cortes histológicos el material fue fijado y deshidratado con alcohol etílico según D`Ambrogio de Argüeso (1986). La inclusión se realizó en paraplast y los cortes con un espesor de $10 \mu \mathrm{m}$. Para la coloración se empleó Hematoxilina de Heindenhain y, para el montaje, Bálsamo de Canadá natural.

Para visualizar los gametangios se colocó el material en una solución de hidrato de cloral con unas gotas de fucsina básica (RodríguezRíos 1973) o carmín acético (Klekowski 1969). La presencia de aceites durante la germinación fue determinada con Sudan IV. Para la 
observación con microscopio electrónico, los gametófitos se fijaron en glutaraldehido al $2.5 \%$ en buffer fosfato y los esporófitos, en F.A.A. (formol, alcohol, ácido acético).

Las frondas juveniles se aclararon con hipoclorito de sodio comercial, diluido en agua en proporción 1:1, y se colorearon mediante la técnica de Foster (1934).

Las observaciones, ilustraciones y fotografías se realizaron con los microscopios Zeiss Standar 16, Zeiss SV 11 y un microscopio electrónico de barrido JEOL modelo JSM 6 480LL.

\section{RESULTADOS}

Esporas: En las cuatro especies estudiadas predominan las esporas triletes, triangulares, con cíngulo ecuatorial, perisporio translúcido y exosporio ornamentado con verrugas en la cara proximal y rugadas con procesos libres o unidos en la cara distal, excepto en $P$. ensiformis que tiene conos en ambas caras.
Además de las triletes, P. cretica (Fig. 1 A-C) y P. multifida (Fig. 1 D-F) presentan esporas atípicas, con varios tipos de aberturas $y$, por lo tanto, de formas variadas. Las esporas pueden ser monoletes, tetraletes e intermedias entre monoletes y triletes o entre triletes y tetraletes. Eventualmente se observaron esporas colapsadas. P. ensiformis (Fig. 1 G) y P. vittata (Fig. $1 \mathrm{H}-\mathrm{I}$ ) tienen solo esporas triletes. En todos los taxones estudiados se presentan esporas translúcidas sin contenido celular y esporas pequeñas, generalmente colapsadas.

El estudio palinológico se resume en el Cuadro 1.

Desarrollo de los gametofitos: El desarrollo del gametófito comienza cuando la primera división ocurre en sentido paralelo al eje ecuatorial de la espora, originándose dos células desiguales: la más pequeña o proximal, en relación con las futuras divisiones, origina el primer rizoide y la distal o célula protálica origina al gametófito.

CUADRO 1

Estudio palinológico

TABLE 1

Palynological studies

\begin{tabular}{|c|c|c|c|}
\hline Especie & $(\mathrm{DP} \times \mathrm{DE}) \mu \mathrm{m}$ & Ornamentación & Morfología (\%) \\
\hline P. cretica & $50-65 \times 35-50$ & Cara distal: rugada. Cara proximal: verrucosa. & $\begin{array}{l}\text { triletes: } 40 \\
\text { monoletes: } 5 \\
\text { tetraletes: } 5 \\
\text { intermedias: } 33 \\
\text { esporas colapsadas o hialinas: } 17\end{array}$ \\
\hline P. ensiformis & $30-60 \times 30-45$ & Conos en ambas caras. & $\begin{array}{l}\text { triletes a globosas: } 85 \\
\text { esporas hialinas: } 15\end{array}$ \\
\hline P. multifida & $40-70 \times 30-40$ & $\begin{array}{l}\text { Cara distal: rugada. } \\
\text { Cara proximal: verrucosa. }\end{array}$ & $\begin{array}{l}\text { triletes: } 79 \\
\text { tetraletes: } 2 \\
\text { monoletes: } 2 \\
\text { intermedias: } 6 \\
\text { esporas colapsadas o hialinas: } 11\end{array}$ \\
\hline P. vittata & $50-80 \times 30-45$ & $\begin{array}{l}\text { Cara distal: reticulada con areolas conteniendo } \\
\text { procesos en su interior. } \\
\text { Cara proximal: verrucosa con procesos unidos } \\
\text { formando muros paralelos al cíngulo ecuatorial. }\end{array}$ & $\begin{array}{l}\text { triletes: } 97 \\
\text { esporas pequeñas colapsadas: } 3\end{array}$ \\
\hline
\end{tabular}



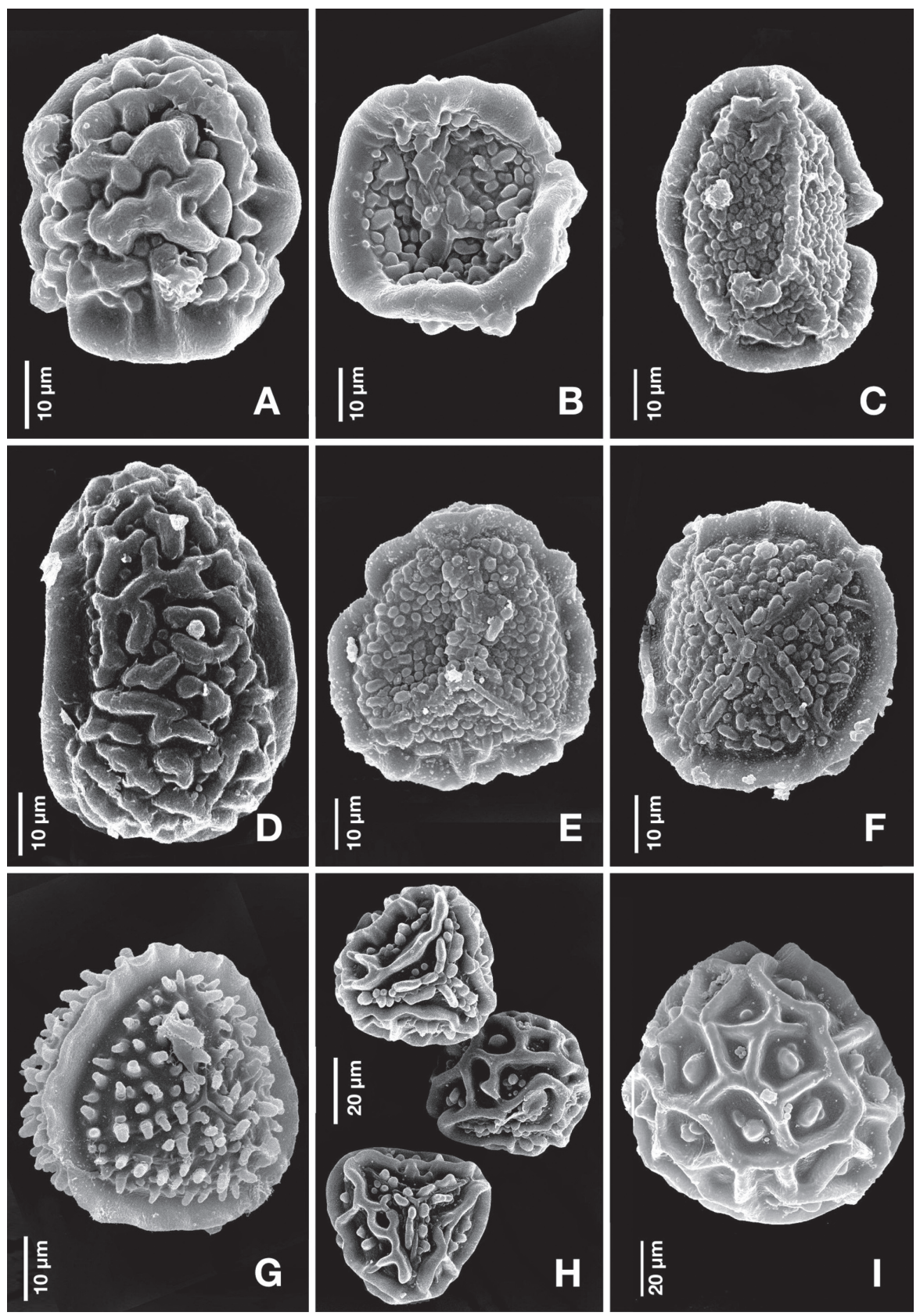

Fig. 1. Esporas de Pteris. A-C: P. cretica. A: Cara distal de espora trilete. B: Cara proximal de espora intermedia entre trilete y tetralete, colapsada. C: Cara proximal de espora intermedia entre trilete y monolete. D-F: P. multifida. D: Cara distal de espora intermedia. E: Cara proximal de esporas trilete. F: Cara proximal de espora tetralete. G: Cara proximal de $P$. ensiformis. H-I: P. vittata. H: Cara proximal de dos esporas y una cara distal en vista ecuatorial. I: Cara distal de espora trilete.

Fig. 1. Pteris spores. A-C: P. cretica. A: Trilete spores distal face. B: Proximal face of intermediate spore between trilete and tetralete, collapsed. C: Proximal face of intermediate spore between trilete and monolete. D-F: P. multifida. D: Intermediate spore distal face. E: Trilete spores proximal face of. F: Tetralete spore proximal face. G: P. ensiformis proximal face. H-I: $P$. vittata. H: Proximal face of two spores and a distal face in equatorial sight. I: Trilete spore distal face. 
El primer rizoide contiene cloroplastos y elaioplastos durante las primeras horas de su crecimiento; luego, estos plástidos se reabsorben y el rizoide se torna incoloro.

La germinación comienza a los 3 días en P. vittata y a los 6-7 días en las otras especies (Fig. 2 A, 3 A). Después de 10 días de realizada la siembra, se observa que el porcentaje de germinación es del $97 \%$ para $P$. vittata, $P$. multifida (35\%), P. ensiformis (30\%) y P. cretica $(25 \%)$.

El tiempo de germinación de las esporas monoletes, tetraletes e intermedias de $P$. cretica y $P$. multifida es semejante al requerido por las esporas triletes.

La germinación no es un proceso sincrónico; ocurre entre los 30-40 primeros días. Sólo las esporas hialinas y colapsadas permanecen sin cambios en el sustrato después de este tiempo.

El desarrollo de gametófitos filamentosos se origina inmediatamente después de la germinación y la dirección del crecimiento es paralela al eje polar de la espora.

Los filamentos son cortos con 3-5 células, en $P$. cretica, $P$. multifida y $P$. vittata (Fig. 2 B) o largos, con 7-9 células, en $P$. ensiformis (Fig. 3 B-C). En esta última especie también se observan células protálicas que permanecen indivisas un par de días, alcanzan la longitud de los protalos filamentosos (Fig. 3 D), luego se tabica y continúa su crecimiento como los otros. Los gametófitos filamentosos desarrollan 1-4 rizoides en las células próximas a la espora.

Este estado perdura 3-4 días; luego, en $P$. cretica y $P$. multifida, la célula distal y la anterior a ésta se dividen en sentido paralelo al eje del filamento y una división oblicua en la célula distal origina una célula meristemática central obcónica.

En $P$. ensiformis y $P$. vittata, la célula distal del filamento y las anteriores a ésta se dividen en sentido paralelo al eje del filamento sin diferenciación de una célula obcónica (Fig. 3 E).

Los gametófitos espatulados son cortos en P. cretica, P. multifida y P. vittata (Fig. 2 C-D) y largos en $P$. ensiformis.
La forma laminar se desarrolla a partir de los 10-14 días desde la siembra de las esporas (Fig. 2 E-F), salvo en $P$. vittata que comienza antes. P. cretica y P. multifida generan gametófitos laminares con una escotadura central donde la célula obcónica central origina un meristemo pluricelular (Fig. 2 G). P. ensiformis y $P$. vittata producen gametófitos laminares amerísticos, asimétricos (Fig. 2 H, 3 F-G) que desarrollan un meristemo pluricelular sobre un lado de la lámina; éste, paulatinamente, queda inserto en una escotadura. La asimetría de los gametófitos laminares de estas dos especies es diferente: $P$. vittata forma hemiláminas semejantes de distintas dimensiones (Fig. $2 \mathrm{~J}-\mathrm{K}$ ) y $P$. ensiformis origina formas irregulares con hemiláminas de morfología variable (Fig. 3 H-L).

Independientemente del tipo de desarrollo gametofítico, a partir de los 14 días se encontraron gametófitos cordiformes con una área central pluriestratificada en las cuatro especies (Fig. 2 L, 3 M).

Los gametófitos maduros, después de los 50 días, emiten en la base 1-3 filamentos, cada uno de los cuales crece y origina un nuevo gametófito laminar (Fig. 2 I). Los nuevos individuos alcanzan rápidamente la forma cordada y se disponen en forma centrípeta uno al lado del otro, sin superponerse. Este proceso se repite en todos los individuos, de manera que se generan colonias con 10 a 40 gametófitos (Fig. $2 \mathrm{M}$ ).

Gametangios: Los gametófitos de las cuatro especies son protándricos. $P$. cretica produce anteridios en la zona media de la lámina a partir de los 14 días; P. ensiformis, P. multifida y $P$. vittata desarrollan anteridios después de los 30 días, cuando los gametófitos alcanzan la forma cordada.

Los anteridios se ubican entre los rizoides o en zonas próximas a éstos. Son del tipo común de los helechos leptosporangiados y están formados por una célula basal, una célula anular y una célula opercular. Tienen forma ovada en $P$. cretica, $P$. ensiformis y $P$. multifida y son más o menos cilíndricos en $P$. vittata (Figs. 5 A-B). $\mathrm{El}$ aspecto de los anteridios responde a la forma 

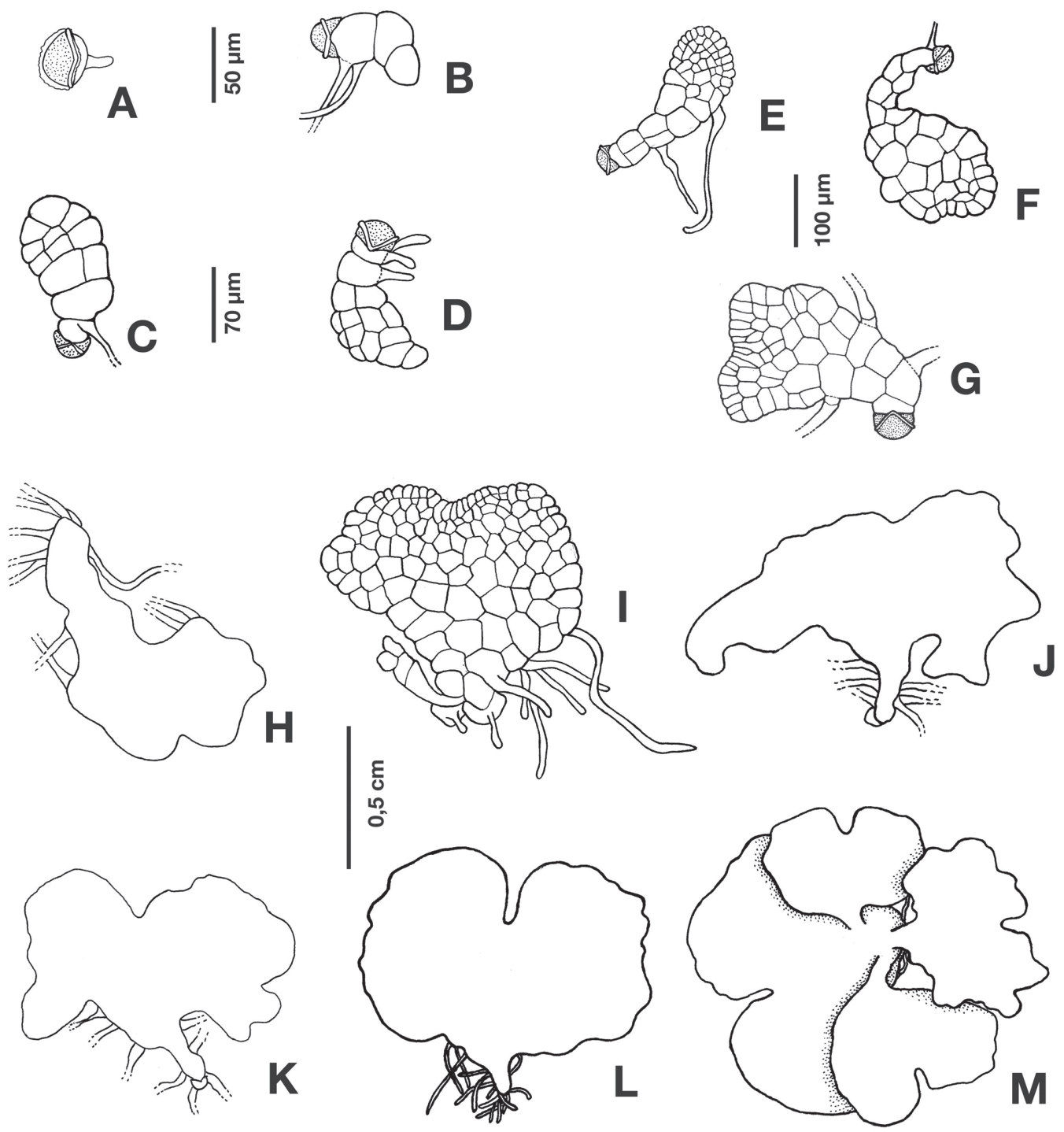

Fig. 2. Desarrollo gametofítico en Pteris. A: Germinación de la espora de P. multifida (6 días). B: Fase filamentosa de $P$. cretica (8 días). C: Gametófito espatulado de $P$. vittata (5 días). D: $P$. vittata (7 días). E-M: Gametófitos laminares. E: $P$. cretica (10 días). F: P. multifida (9 días). G: P. multifida (10 días). H: $P$. vittata (14 días). I: P. cretica (52 días). J: $P$. vittata (30 días). K: $P$. vittata (30 días). L: P. cretica (30 días). M: $P$. multifida (80 días).

Fig. 2. Gametophyte development in Pteris. A: P. multifida spore germination (6 days). B: P. cretica filament stage (8 days). C: $P$. vittata (spatulate gametophyte of 5 days). D: P. vittata (7 days). E-M: Laminar stage. E: P. cretica (10 days). F: $P$. multifida (9 days). G: P. multifida (10 days). H: P. vittata (14 days). I: P. cretica (52 days). J: P. vittata (30 days). K: P. vittata (30 days). L: P. cretica (30 days). M: P. multifida (80 days). 

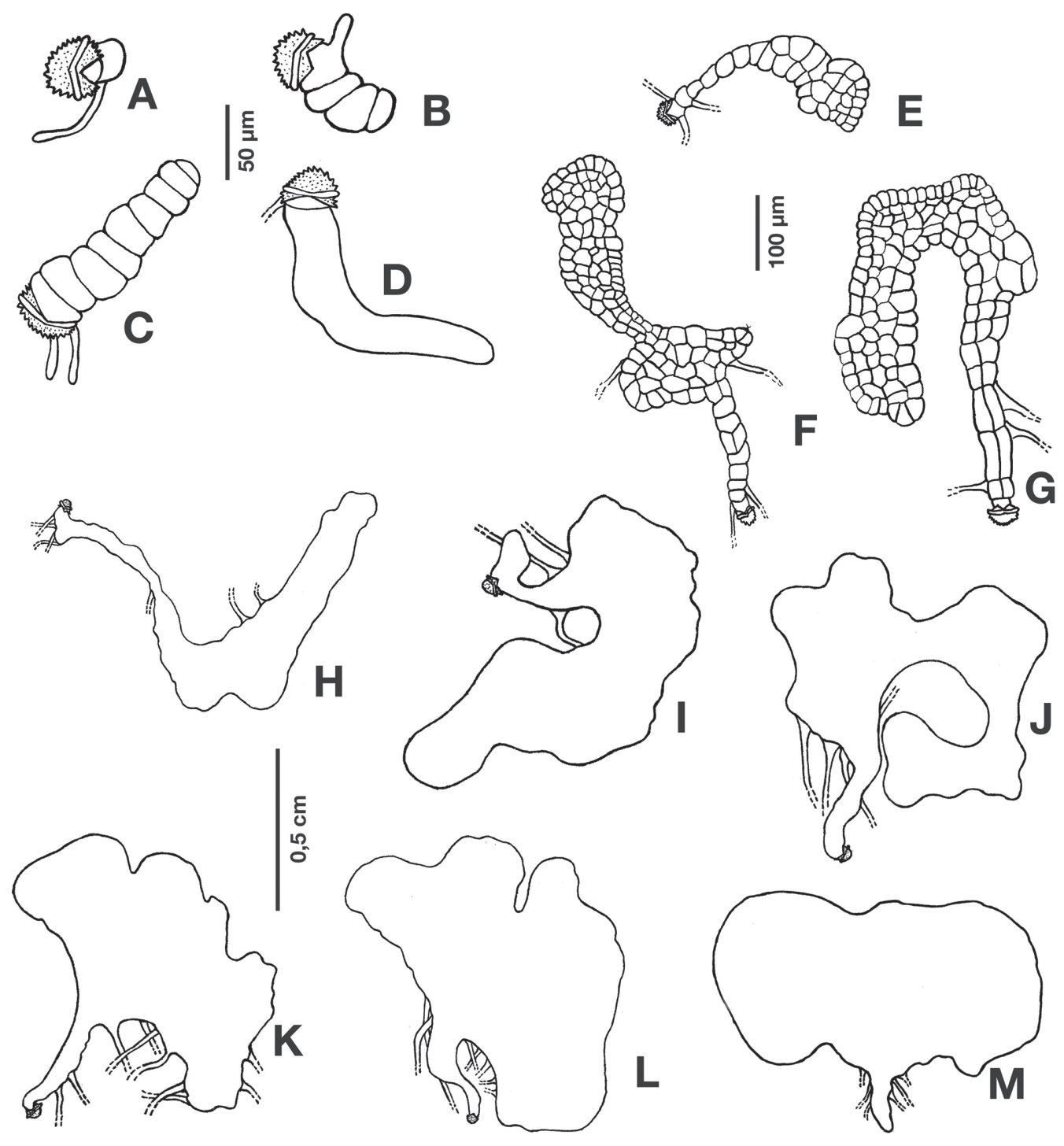

Fig. 3 Desarrollo gametofítico en P. ensiformis. A: Germinación de la espora (7 días). B-C: Fase filamentosa. B: Filamento joven ( 8 días). C: Filamento con nueve células (10 días). D: Célula protálica larga (10 días). E-M: Fase laminar. E: gametófito asimétrico (12 días). F-J: gametófitos irregulares: F-G: 20 días. H: 25 días. I: 27 días. J: 30 días. K-L: Gametófitos laminares asimétricos (30-35 días). M: Gametófito adulto (35 días).

Fig. 3. P. ensiformis gamethophyte development. A: Spore germination (7 days). B-C: Filament stage. B: Young filament (8 days). C: Nine-cell filament (10 days). D: Long protalic cell (10 days). E-M: Laminar stage. E: Asymmetric gametophyte (12 days). F-J: Irregular gametophytes. F-G: 20 days. H: 25 days. I: 27 days. J: 30 days. K-L: Asymmetric laminar gametophyte (30-35 days). M: Adult gametophyte (35 days). 


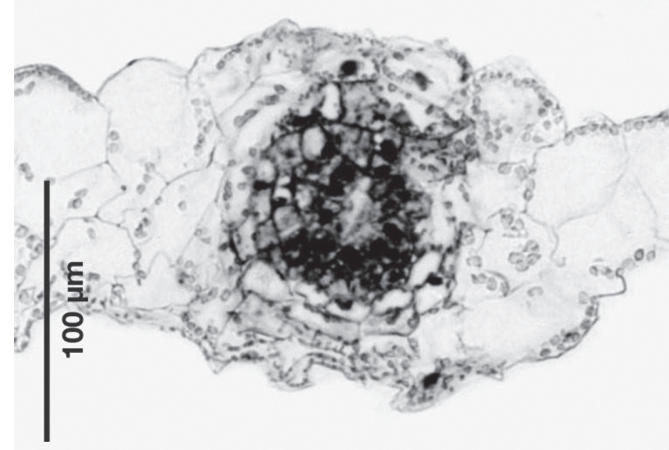

Fig. 4. Anteridios de P. vittata. A: Anteridios sobre el lado abaxial del gametófito adulto (50 días). B: Detalle de anteridio con célula anular cilíndrica (50 días).

Fig. 4. P. vittata antheridia. A: Adult gametophyte abaxial side antheridia (50 days). B: Detail of antheridium with cylindric annular cell (50 days).

de la célula anular, que es la que predomina en este gametangio.

Los arquegonios se han encontrado a partir de los 40 días en $P$. ensiformis, P. multifida y $P$. vittata. Estos gametangios se ubican sobre el lado abaxial del área central, próximos a la escotadura de la lámina. Los cuellos de los arquegonios están formados por 4 hileras de 4 células cada una. $P$. cretica no desarrolló arquegonios.

Es frecuente que los gametófitos repicados durante un año formen costillas bifurcadas, gametangios en ambos lados del gametófito y sobre las hemiláminas. En $P$. multifida se han encontrado callos que se originan en el área central como masas blanquecinas que se extienden hasta reemplazar completamente al gametófito.

Esporófitos: Los esporófitos se evidencian a partir de los 3 meses. La primera evidencia de la formación de un embrión ocurre a partir de los 30 días con la aparición de un mamelón sobre la cara abaxial del área central, por debajo del cuello del gametófito (Fig. 4).

En $P$. cretica, esta protuberancia está cubierta por escamas clatradas y castañas, de la que emergen entre 2 y 5 circinos que se despliegan hacia el ápice (Fig. 6 E). Las restantes especies originan 1-2 esporófitos por cada gametófito (Fig. 6 A). En todos los casos, sólo uno de ellos se desarrolla.
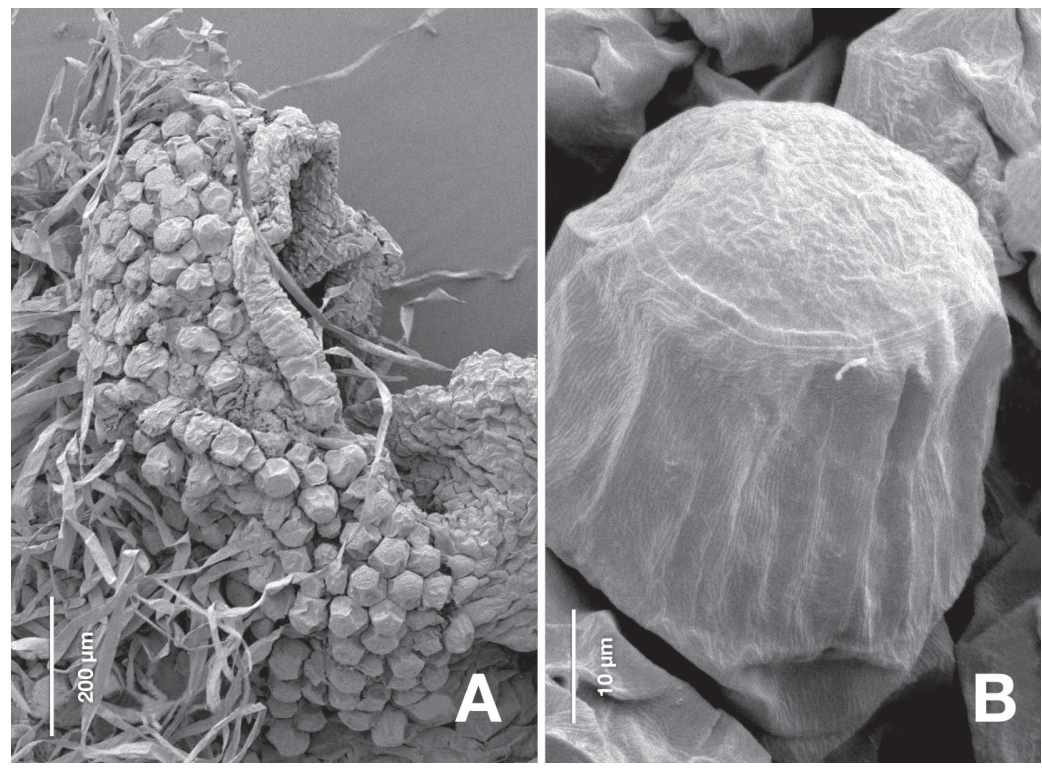

Fig. 5. Corte transversal del gametófitos adulto de P. cretica mostrando meristemo en área central. (30 días).

Fig. 5. Cross section of P. cretica, the adult gametophyte showing a central area meristem (30 days). 

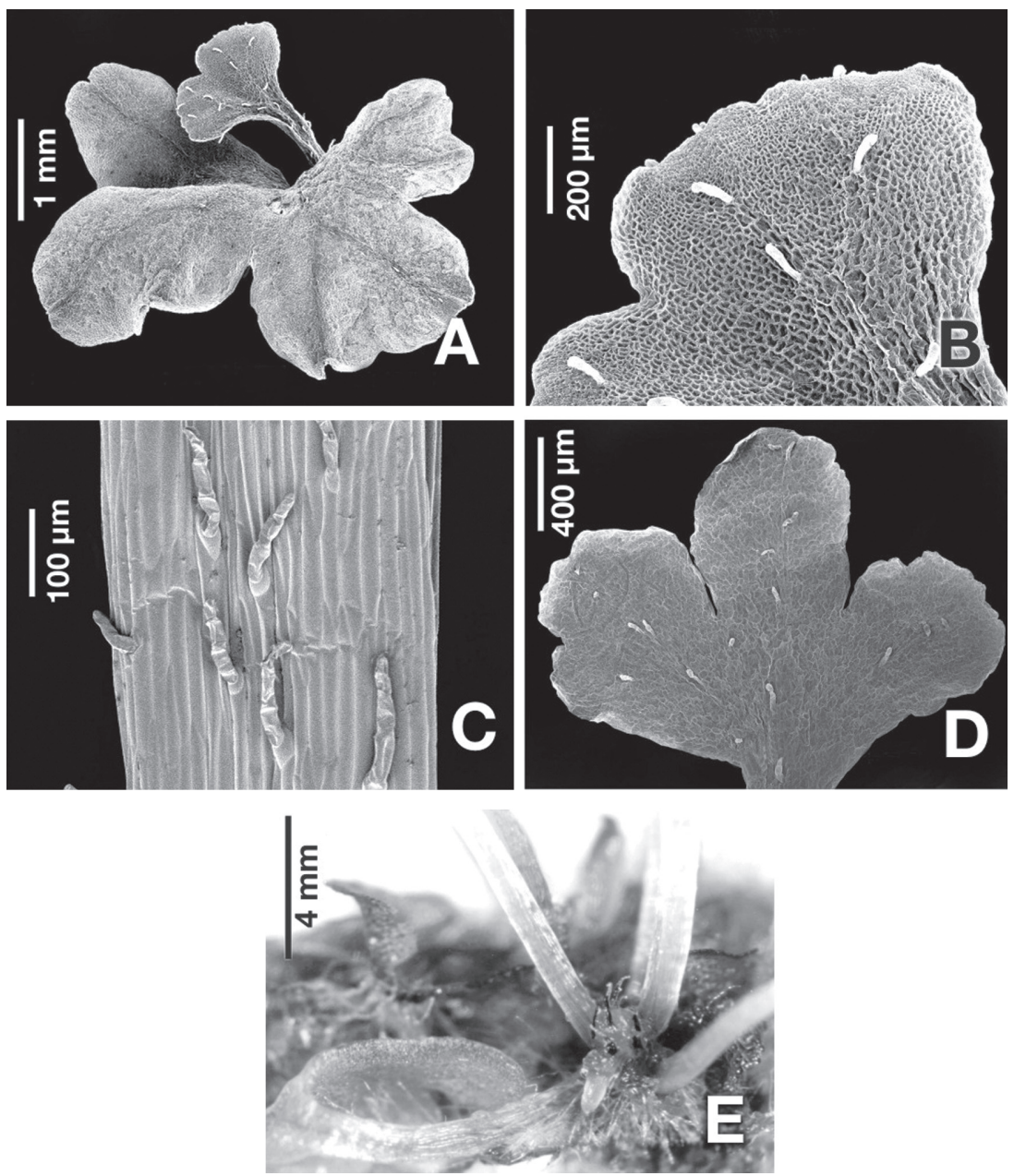

Fig. 6. Esporofitos de Pteris. A: Dos esporófitos de P. vittata en un gametófito (120 días). B: Lámina de P. vittata con tricomas 2-3 celulares (120 días). C: Esporófito de P. multifida con tricomas pluricelulares en pecíolo de esporófito joven (120 días). D: Lámina de P. cretica con tres lóbulos (140 días). E: Gametófito de P. cretica con cuatro esporófitos en desarrollo (120 días).

Fig. 6. Pteris sporophytes. A: Two $P$. vittata sporophytes in one gametophyte (120 days). B: $P$. vittata lamina with trichome 2-3 cellulars (120 days). C: P. multifida sporophytes, with multicellular trichomes in petiole of young sporophyte (120 days). D: Laminae with $P$. cretica three lobes sporophyte (140 days) E: P. cretica gametophytes with four sporophytes in development (120 days).

La primera fronda que emerge tiene vernación circinada, lámina de contorno triangular, margen entero y venas libres; el pecíolo es translúcido, 6-8 veces más largo que la lámina y de sección circular. El indumento está representado por tricomas en toda la superficie de la lámina y el pecíolo. P. multifida tiene tricomas
4-6 celulares (Fig. 6 C) y las restantes especies 2-3 celulares (Fig. 6 B, D).

Aproximadamente a los 100 días, la lámina aumenta de tamaño y se forman dos o tres lóbulos con senos evidentes en las terminaciones de las venas; el margen se mantiene entero y la venación dicótoma, libre (Figs. 6 A, D; 7 A-B). 
Cuando la lámina alcanza mayor tamaño, los segmentos se ensanchan y aumentan el número de lóbulos (Fig. 7 C); luego, el segmento apical se mantiene indiviso, su base es decurrente sobre el raquis y sus segmentos basales continúan dividiéndose (Figs. 7 G-H) hasta alcanzar la arquitectura de la lámina adulta. La venación dicótoma se mantiene, los tricomas se limitan al raquis y a las venas y el margen entero se transforma en aserrado (Figs. 7 D-F, 8). Las láminas son hipostomáticas con estomas polocíticos y las células epidérmicas de contorno sinuoso adquieren, paulatinamente, las ondulaciones del patrón adulto. A los 120 días, la fronda joven tiene la estructura de la planta adulta.

\section{DISCUSIÓN}

El estudio palinológico realizado en $P$. cretica, $P$. ensiformis, $P$. multifida y $P$. vittata muestra que estas especies comparten el predominio de esporas triletes y tienen un bajo porcentaje (entre 3 y17\%) de esporas hialinas y colapsadas, coincidentes con la cantidad de esporas no germinadas en el medio de cultivo.

La morfología de las esporas atípicas (monoletes, tetraletes e intermedias) en $P$. cretica y $P$. multifida no influye en la viabilidad, por lo que estas esporas germinan en lapsos similares a las de $P$. ensiformis y otras especies de Pteris (Mendoza et al. 1997, Zhang et al. 2008 y Prada et al. 2008).

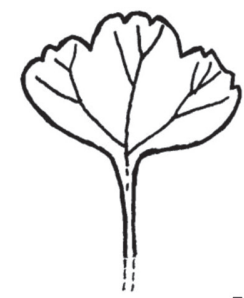

A

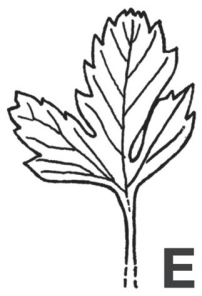

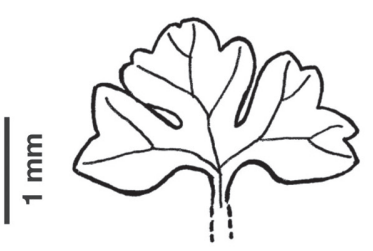

B
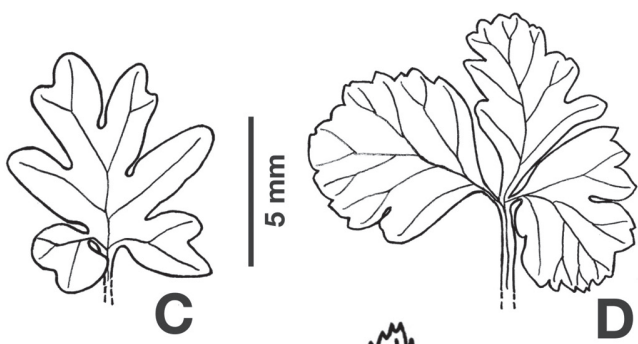

D
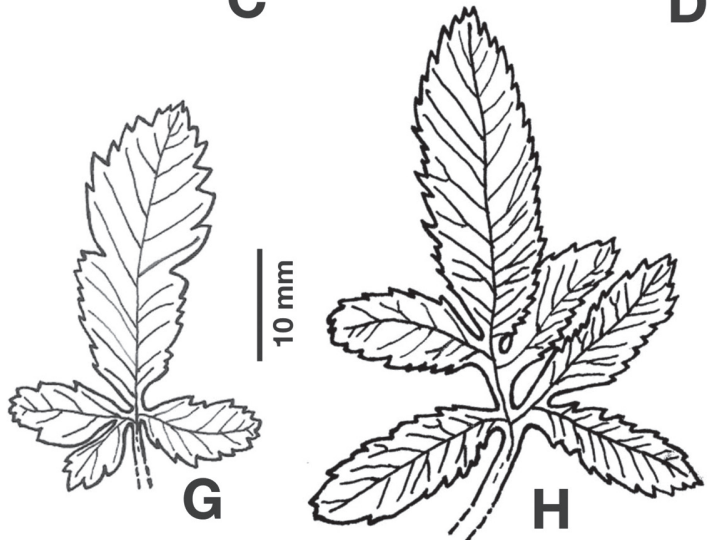

Fig. 7. Láminas de esporófitos jóvenes de Pteris. A: Lámina con tres lóbulos incipientes de P. cretica (100 días). B: Lámina con lóbulos marcados de $P$. cretica (110 días). C: Lámina lobulada de $P$. ensiformis (114 días). D: Lámina con tres lóbulos de margen dentado de $P$. vittata (120 días). E: Lámina con margen aserrado de P. multifida (110 días). F: Lámina con tres lóbulos separados de P. multifida (114 días). G: Lámina con lóbulo basal dividido de P. multifida (120 días). H: Lámina pinnada de $P$. multifida (130 días).

Fig. 7. Pteris young sporophyte laminae. A: P. cretica lamina with three incipient lobes (100 days). B: P. cretica lamina with marked lobes (110 days). K: Lobulate lamina of $P$. ensiformis (114 days). L: P. vittata lamina with three lobes of dentate margin (120 days). M: P. multifida lamina with serrulate margin (110 days). N: P. multifida lamina with three separated lobes (114 days). O: P. multifida lamina with divided basal lobe (120 days). P: P. multifida pinnate lamina (130 days). 


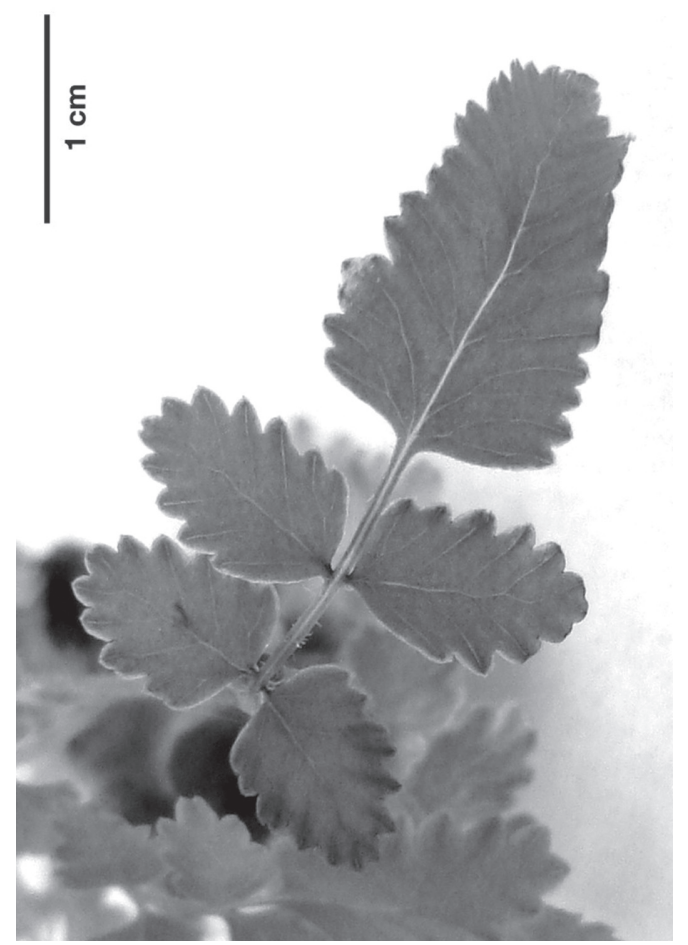

Fig. 8. Esporófito de P. vittata mostrando lámina con 4 segmentos de margen aserrado (150 días).

Fig. 8. P. vittata sporophytes showing 4 segments with serrulate margin lamina (150 days).

El tipo de germinación, en las cuatro especies, corresponde al tipo Vittaria según el criterio propuesto por Nayar \& Kaur (1968). Este patrón de germinación es muy frecuente (Nayar \& Kaur 1971) y ha sido mencionado para otras especies tales como $P$. berteroana (Mendoza et al. (1997), P. chilensis (Letelier \& Peñailillo 2007), P. incompleta (Prada et al. 2008), P. finotti, P. fauriei, P. excelsa Gaudich., P. wallichiana (Zhang et al. 2008).

La célula rizoidal que emerge en la germinación, contiene plástidos en los primeros momentos de su crecimiento; ésta característica ha sido descrita también para $P$. fauriei (Zhang et al. 2008).

Las esporas de las cuatro especies germinan entre los 3 y 7 días después de la siembra mientras que otras especies del mismo género necesitan entre los 8 y 12 (Kawakami et al. 1995, Mendoza et al. 1997, Letelier \& Peñailillo 2007). Esto ocurre, probablemente, porque las siembras se realizaron durante las dos primeras semanas desde su colecta, lo que evita cambios bioquímicos producidos por el almacenamiento (Beri \& Bir 1993).

La capacidad de germinación se extiende hasta los 40 días, excepto en $P$. vittata donde se registra el $97 \%$ de germinación en los 10 primeros días de realizada la siembra, dato comparable al resultado logrado por Beri \& Bir (1993) y Prada et al. (2008).

Los resultados de la morfogénesis indican que $P$. cretica, $P$. multifida y $P$. vittata tienen gametófitos filamentosos con 3-5 células, característica encontrada en $P$. berteroana, $P$. fauriei y $P$. wallichiana J. Agardh (Mendoza et al. 1997). Zhang et al. (2008) reportan gametófitos con 2 a 19 células para $P$. vittata y hasta 25 células para $P$. ensiformis en material proveniente de China. En el material de origen americano, esta última especie produce entre 7-9 células.

El desarrollo gametofítico de $P$. cretica y P. multifida corresponde al tipo Adiantum según la clasificación propuesta por Nayar \& Kaur (1969). Dichos autores mencionan a este tipo como característico de Adiantum L., Cheilanthes Sw. y Doryopteris J. Sm., entre otros. Atkinson (1973) lo describe para $P$. tremula R. Br. y P. multifida.

Nayar \& Kaur (1969) consideran que el tipo Ceratopteris es característico de Pteris y Atkinson (1973) lo encuentra en P. longifolia L., P. grandifolia L. y P. comans G. Forst. En este trabajo se encuentra que $P$. ensiformis y $P$. vittata responden a ese tipo de crecimiento. Las formas irregulares de los gametófitos laminares de Pteris ensiformis no se podrían asociar a la ploidía, por cuanto las cuatro especies estudiadas son poliploides (Walker 1962, Zhong-Ren 1989).

El desarrollo de gametófitos monoicos protándricos en $P$. ensiformis, $P$. multifida y $P$. vittata favorece el cruzamiento en las especies con reproducción sexual, hecho considerado 
por Klenkowski (1969) como la forma más frecuente entre los helechos homospóricos.

La estructura de los anteridios, en general, ha sido poco registrada mediante microscopía electrónica. Tanco et al. (2009) muestran anteridios de $P$. inermis donde se observan estos gametangios de aspecto ovoide semejantes a los encontrados en $P$. cretica, $P$. ensiformis y $P$. multifida. $P$. vittata tiene anteridios netamente cilíndricos; similar forma se observa en una fotografía presentada por Zhang et al. (2008) para esta especie.

En $P$. cretica es curiosa la aparición de anteridios en etapas muy tempranas del desarrollo gametofítico, pues esto indicaría la existencia de anteridiógenos (Raghavan 1989) que, en este caso, son innecesarios al no originarse arquegonios.

Los cuellos de los arquegonios en $P$. ensiformis, $P$. multifida y $P$. vittata tienen 16 células y son semejantes a los de $P$. cretica (Laird $\&$ Sheffield 1986) y $P$. inermis (Tanco et al. 2009). Zhang et al. (2008) menciona cuellos de arquegonios formados por 4 hileras con 3-5 células en cada anillo.

Previo al desarrollo de esporófitos se han registrado traqueidas en todas las especies estudiadas. Esta característica ha sido asociada inicialmente a la apogamia por Atkinson \& Stokey (1964). En el material estudiado, $P$. cretica es apogámica debido a la formación únicamente de gametófitos anteridiados.

Según Walker (1962), P. cretica es una especie constantemente apogámica tanto en ejemplares diploides y triploides como en tetraploides $(n=58$ y $2 n=c .120)$ y señala que es frecuente que las especies apogámicas produzcan arquegonios no funcionales, característica demostrada por Laird \& Sheffield (1986) al determinar que las células del canal del cuello de los arquegonios colapsan, evitándose de esta manera el desplazamiento de los anterozoides a la ovocélula.

La formación de esporófitos apogámicos en $P$. cretica podría explicar su distribución cosmopolita, pues no depende de las condiciones ambientales propicias para una reproducción sexual.
Los esporófitos, provenientes tanto de reproducción sexual como apogámica, tienen el mismo patrón de desarrollo y alcanzan la estructura de las plantas adultas después de los 120 días de realizada la siembra.

Estos aportes provenientes de la morfogénesis de los gametófitos y esporófitos de $P$. cretica, $P$. ensiformis, $P$. multifida y $P$. vittata podrán ampliar las características taxonómicas del género Pteris y sus posibles relaciones con otros helechos, como lo sugieren Atkinson \& Stokey (1964).

\section{AGRADECIMIENTOS}

Agradezco a Cristina Bonomo por facilitar equipamiento para este estudio, a María del Carmen Otero por el delineado de los dibujos con tinta china, a Pedro Villagrán por las atenciones durante el servicio de Microscopía Electrónica de Barrido, a Silvia Sastre por las correcciones del texto en inglés. A los revisores anónimos por las sugerencias brindadas para mejorar el manuscrito. Este trabajo fue financiado por el Consejo de Investigación de la Universidad Nacional de Salta (Argentina) Proyecto $\mathrm{N}^{\circ} 1585$.

\section{RESUMEN}

El género pantropical Pteris L. tiene 250 especies de la cuales 60 están en el continente Americano. Se estudió la morfogénesis de los gametófitos, y la morfología de los esporófitos jóvenes de cuatro especies: $P$. cretica, $P$. ensiformis, $P$. multifida y P.vittata, junto con un análisis palinológico que incluye la capacidad de las esporas de germinar. Los gametófitos se obtuvieron mediante técnicas de cultivo in vitro. Los esporófitos jóvenes se trasladaron a sustrato estéril de tierra y arena (3:1). Se usó el microscopio de luz y el de barrido (SEM). Se encontraron esporas con diferentes tipos de aperturas. La germinación ocurre entre 3-7 días y corresponde al tipo Vittaria. Se encontraron gametófitos filamentosos formados por 3-5 células en P. cretica, $P$. multifida y $P$. vittata y por 7-9 células en $P$. ensiformis. El desarrollo gametofítico ocurre de dos formas: tipo Adiantum y tipo Ceratopteris. Los gametófitos de $P$. ensiformis, $P$. multifida y P. vittata son monoicos y protándricos. $P$. cretica desarrolla gametófitos anteridiados. Los anteridios corresponden al tipo común de los helechos leptosporangiados, son cilíndricos en $P$. vittata y ovoides en las otras tres especies. Los cuellos de los arquegonios 
tienen 4 hileras con 4 células cada una. Los esporófitos se desarrollan después de los 3 meses de su siembra y su indumento es semejante a las plantas adultas. P. cretica presenta apogamia obligada.

Palabras claves: Pteris, esporas, desarrollo gametofítico, esporófitos jóvenes, apogamia.

\section{REFERENCIAS}

Arreguín-Sanchez, M. de la L., R. Palacios-Chaves \& D.L. Quiróz-García. 1997. Morfología de las esporas del género Pteris para Mexico. Phytologia 83: 67-78.

Atkinson, L.R. 1973. The gametophyte and family relationships. J. Linn. Soc. Bot. 67: 73-90.

Atkinson, L.R. \& A.G. Stokey. 1964. Comparative morphology of the gametophyte of homosporous ferns. Phytomorphology 14: 51-70.

Beri, A. \& S.S. Bir. 1993. Germination of stored spores of Pteris vittata L. Amer. Fern J. 83: 73-78.

D’Ambrogio de Argüeso, A. 1986. Manual de Técnicas en Histología Vegetal. Hemisferio Sur, Buenos Aires, Argentina.

Devi, S. 1977. Spores of Indian ferns. Today \& Tomorrow’s, New Delhi, India.

Erdtman, G. \& P. Sorsa. 1971. Pollen and spore morphology and plant taxonomy-Pteridophyta, text and additional illustrations. Almquist \& Wiksell, Estocolmo, Suecia.

Foster, A.S. 1934. The use of tannic acid and iron chloride for staining cell walls in meristematic tissue. Stain Technol. 9: 91-92.

Huang, T.C. 1981. Spore Flora of Taiwan. Botany Dept. Natl. Tah-Jinn, Taiwán.

Huang, Y.M., H.M. Chou, T.H. Hsieh, J.C. Wang \& W.L. Chiou. 2006. Cryptic characteristics distinguish diploid and triploid varieties of Pteris fauriei (Pteridaceae). Can. J. Bot. 84: 261-268.

Ito, M. 1962. Studies on the differentiation of fern gametophytes. I. Regeneration of single cells isolated from cordate gametophytes of Pteris vittata. Bot. Mag. Tokyo 75: 19-27.

Kato, Y. 1963. Physiological and morphogenetic studies of fern gametophytes in aseptic culture. I. callus tissues from dark-cultured Pteris vittata. Bot. Gazette 124: 413-416.
Kato, Y. 1969. Physiological and morphogenetic studies of fern gametophytes and sporophytes in aseptic culture. VII. Experimental modifications of dimensional growth in gametophytes of Pteris vittata. Phytomorphology 19: 114-121.

Kawakami, S.M., M. Ito \& S. Kawakami. 1995. Apogamous sprophyte formation in a fern P. multifida and its characteristics. J. Plant Res. 108: 181-184.

Klekowski, E.J. Jr. 1969. Reproductive biology of the Pteridophyta. II. Theorical considerations. Bot. J. Linn. Soc. 62: 347-359.

Laird, S. \& E. Sheffield. 1986. Antheridia and archegonia of the apogamous fern P. cretica. Ann. Bot. 57: 139143.

Lellinger, D.B. \& W.C. Taylor. 1997. A classification of spore ornamentation in the Pteridophyta, p. 33-42. In J.M. Camus, M. Gibby \& R.J. Johns (eds.). Pteridology in Perspective. Royal Botanic Gardens, Kew, Reino Unido.

Leterier, L. \& P. Peñailillo. 2007. Desarrollo del gametofito y esporófito joven de Pteris chilensis Desv. (Pteridaceae-Pteridophyta). Gayana Bot. 64: 93-97.

Martínez, O.G. \& M.A. Morbelli. 2009. The spores of Pteris cretica complex (Pteridaceae-Pteridophyta) in America. Grana. 48(3): 193-214.

Mendoza, A., B. Pérez-García, I. Reyes Jaramillo \& M. Ricci. 1997. Desarrollo del gametofito de Pteris berteroana (Pteridaceae: Pterideae). Rev. Biol. Trop. 44/45:51-57.

Michelena, I.G. 1989. Esporas de la Familia Adiantaceae (Pteridophyta) de la Provincia de Buenos Aires, Argentina. Bol. Asoc. Latinoam. Paleobot. Palinología 12: 25-31.

Nayar, B.K., P. Lata \& L.P. Taiwari. 1964. Spore morphology of the ferns of west Tropical Africa. Pollen Spores 6: $545-582$

Nayar, B.K. \& S. Devi. 1966. Spore morphology of the Pteridaceae I. The Pteridoid ferns. Grana Palynol. 6: 476-503

Nayar, B.K. \& S. Kaur. 1968. Spore germination in homosporous ferns. J. Palynol. 4: 1-14.

Nayar, B.K. \& S. Kaur. 1969. Types of prothallial development in homosporous ferns. Phytomorphology 19: 179-188.

Nayar, B.K. \& S. Kaur. 1971. Gametophytes of homosporous ferns. Bot. Rev. 37: 295-396. 
Prada, C., V. Moreno \& J.M. Gabriel y Galán. 2008. Gametophyte development, sex expression and antheridiogen system in Pteris incompleta Cav. Amer. Fern J. 98: 14-25.

Punt, W., P.P. Hoen, S. Blackmore, S. Nilsson (†) \& A. Le Thomas. 2007. Glossary of pollen and spore terminology. Paleobot. Palynol. 143:1-81. (también disponible en línea: www.sciencedirekt.com)

Raghavan, V. 1989. Developmental biology of fern gametophytes, p. 361. In P.W. Barlow, D. Bray, P.B. Green \& J.M.W. Slack (eds.). Developmental and cell biology series. Cambridge University, Cambridge, Londres.

Rodríguez Ríos, R. 1973. Morfología de los gametófitos y esporófitos jóvenes de algunas especies chilenas de Blechnum (Polypodiaceae s. 1.). Gayana Bot. 22: 1-30.

Sladkov, A.N. 1957. Spore polymorphism in P. cretica. U.S.S.R. Acad. Sci. 177: 900-903.

Smith, A.R., K.M. Pryer, E. Schuettplz, P. Korall, H. Schneider \& P.G. Wolf. 2006. A classification for extant fern. Taxon 55: 705-731.
Steeves, T.A., I.M. Sussex \& C.R. Partanen. 1955. In vitro studies on abnormal growth of prothalli of the bracken fern. Amer. J. Bot. 42: 232-245.

Tanco, M.E., O.G. Martínez, \& M.C. Bonomo. 2009. Germinación y morfogénesis gametofitica de Pteris inermis (Rosenst.) de la Sota. Gayana Bot. 66: 10-17.

Tryon, R.M. \& A.F. Tryon. 1982. Ferns and allied plants with special reference to tropical America. Nueva York Springer, Nueva York, EEUU.

Tryon, R.M. \& B. Lugardon. 1991. Spores of the Pteridophyta: surface, wall structure and diversity based on electron microscope studies. Nueva York Springer, Nueva York, EEUU.

Walker, T.G. 1962. Cytology and evolution in the fern genus Pteris L. Evolution 16: 27-43.

Zhang, K.M., L. Shi, X.C. Zhang, C.D. Jiang \& W.L. TimChun. 2008. Gametophyte morphology and development of six Chinese species of Pteris (Pteridaceae). Amer. Fern J. 98: 33-41.

Zhong-Ren, W. 1989. A preliminary study on cytology of Chinese Pteris. Acta Phytotaxonomica Sinica 27: 421-438. 